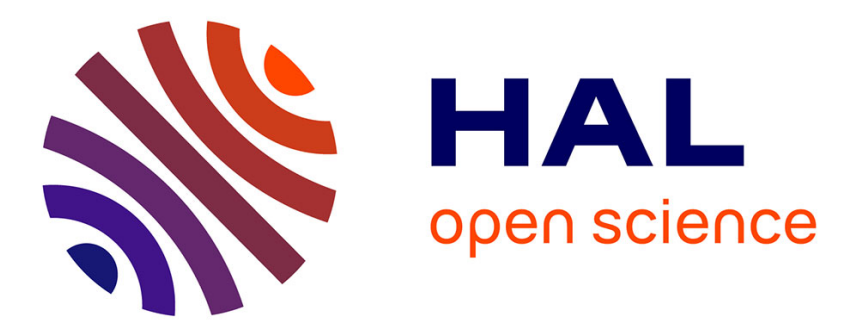

\title{
L2-Orthogonal ST-Code Design for Multi-h CPM with fast Decoding
}

Miguel Angel Hisojo, Jerome Lebrun, Luc Deneire

\section{To cite this version:}

Miguel Angel Hisojo, Jerome Lebrun, Luc Deneire. L2-Orthogonal ST-Code Design for Multi-h CPM with fast Decoding. 2013 IEEE European School of Information Theory, Apr 2013, Ohrid, Macedonia.

2013. hal-01251193

\section{HAL Id: hal-01251193 \\ https://inria.hal.science/hal-01251193}

Submitted on 5 Jan 2016

HAL is a multi-disciplinary open access archive for the deposit and dissemination of scientific research documents, whether they are published or not. The documents may come from teaching and research institutions in France or abroad, or from public or private research centers.
L'archive ouverte pluridisciplinaire HAL, est destinée au dépôt et à la diffusion de documents scientifiques de niveau recherche, publiés ou non, émanant des établissements d'enseignement et de recherche français ou étrangers, des laboratoires publics ou privés. 


\section{L2-Orthogonal ST-Code Design for Multi-h CPM with fast Decoding}

Miguel Angel Hisojo, Jérôme Lebrun, Luc Deneire

I3S Lab. CNRS University of Nice Sophia Antipolis, France

\section{Abstract}

CPM: favorable trade-off between power and bandwidth efficiency

$\oplus$ Multi- $h$ CPM: generalization to further decrease the need for bandwidth.

Difficult decoding in multi-path environments with no diversity

How to overcome these limitations:

IDEA: To combine CPM with Space-Time Block Coding (STBC)

$\rightarrow$ Non trivial extension to $L^{2}$-orthogonal Space-Time codes provides full diversity and better spectra

$\rightarrow$ Decoding complexity greatly decreased. [1][2]

The System Model

M-ary multi- $h$ MIMO system of $L_{t} \times L_{r}$

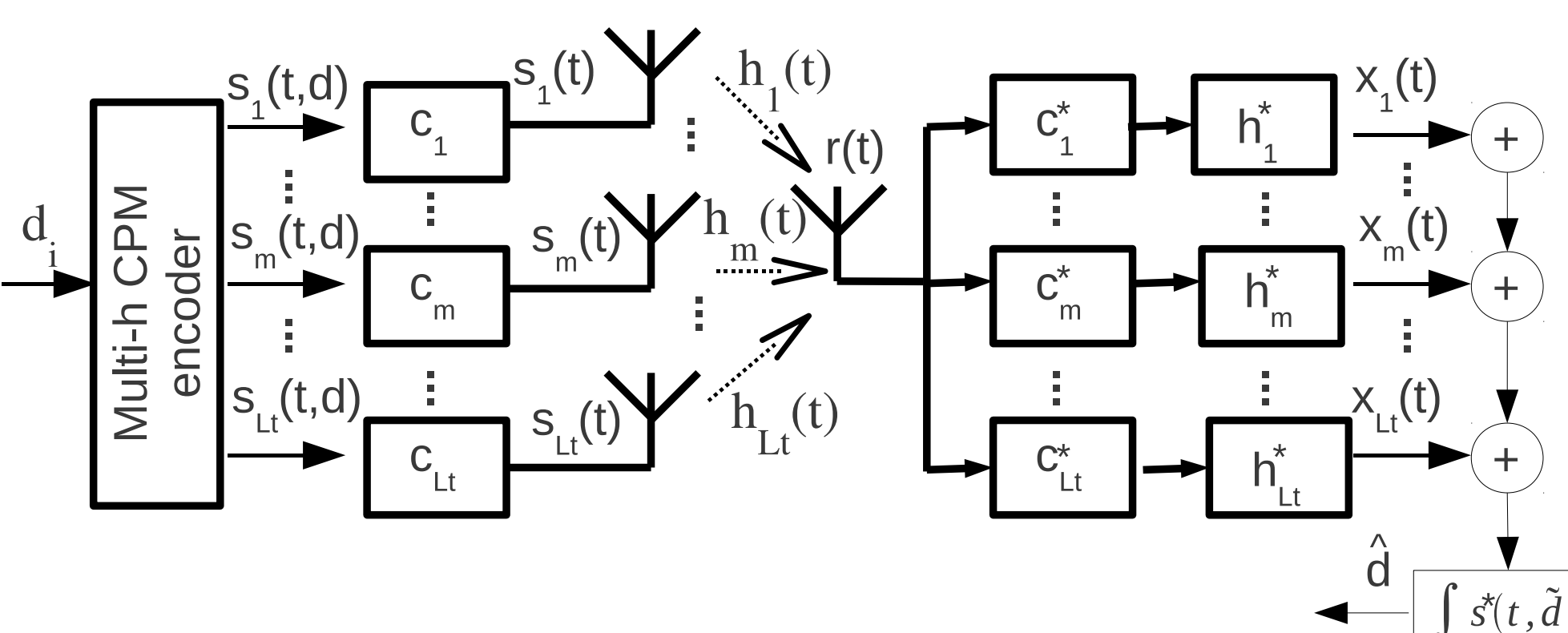

$\mathbf{r}(t, \mathbf{d})=\mathbf{H s}(t, \mathbf{d})+\mathbf{n}(t)$

$\mathbf{r}(t, \mathbf{d})_{\left(L_{r} \times 1\right)}, \mathbf{s}(t, \mathbf{d})\left(_{\left(L_{x} \times 1\right)}\right.$

$\mathbf{H}_{\left(L_{r} \times L_{t}\right)}$ with elements $h_{n, t}$

n $(t)$ AWGN

Thector of transmitted signals:

$\mathbf{s}(t, \mathbf{d})=\left[\mathbf{s}_{l}(t, \mathbf{d}) \ldots \mathbf{s}_{L_{t}}(t, \mathbf{d})\right]^{T}$

$$
\begin{aligned}
& \text { The baseband general form [3] } \\
& \qquad s(t, \mathbf{d})=\sqrt{\frac{E_{s}}{T}} \exp (j \phi(t, \mathbf{d}))
\end{aligned}
$$

$\begin{array}{ll}\text { The information-carrying phase function } & \begin{array}{l}\text { The phase continuity is ensured by the phase } \\ \text { pulse } q(t),\end{array}\end{array}$

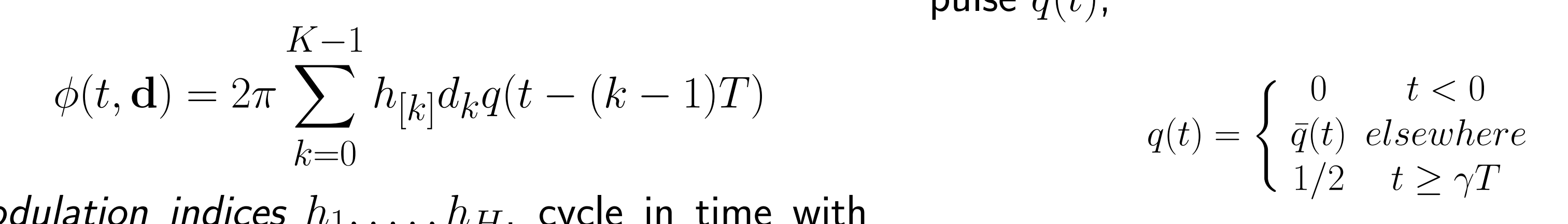

modulation indices $h_{1}, \ldots, h_{H}$, cycle in time with period $H$ as:

$$
[k]=\bmod (k, H)+1
$$

$\bar{q}(0)=0, \bar{q}(\gamma T)=1 / 2$ and $\lim _{t \rightarrow \tau} \bar{q}(t)=\bar{q}(\tau)$ for $0 \leq \tau<\gamma T$. $\gamma$ is the overlapping factor and

$h_{[k]}$ quotient between two relative prime integers.

$$
H_{k}=\left(h_{1}, h_{2}, \ldots, h_{k}\right)=\left(\frac{p_{1}}{q}, \frac{p_{2}}{q}, \ldots, \frac{p_{k}}{q}\right)
$$

\section{$L^{2}$ Orthogonality}

$\mathrm{T}_{\mathrm{T}}^{\mathrm{Y}} \overbrace{Y}^{Y}$

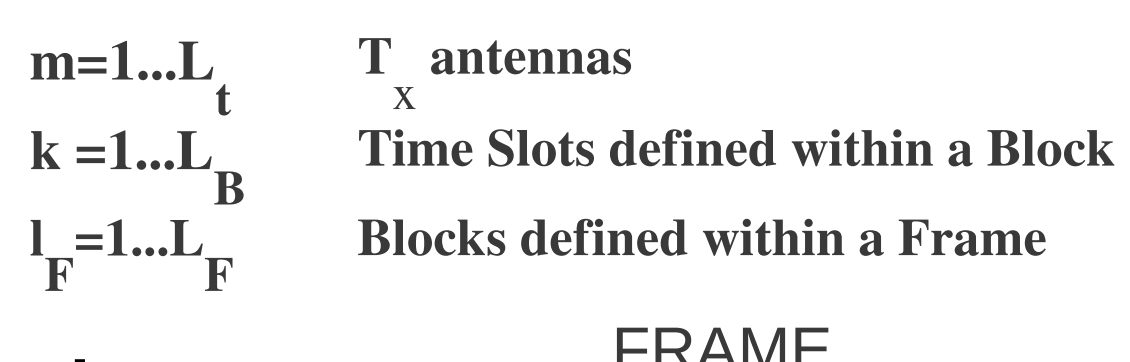

Based on $\|\mathbf{s}\|_{L^{2}}^{2}=\int \mathbf{s}(t) \mathbf{s}^{H}(t) d t$, each block fulfills

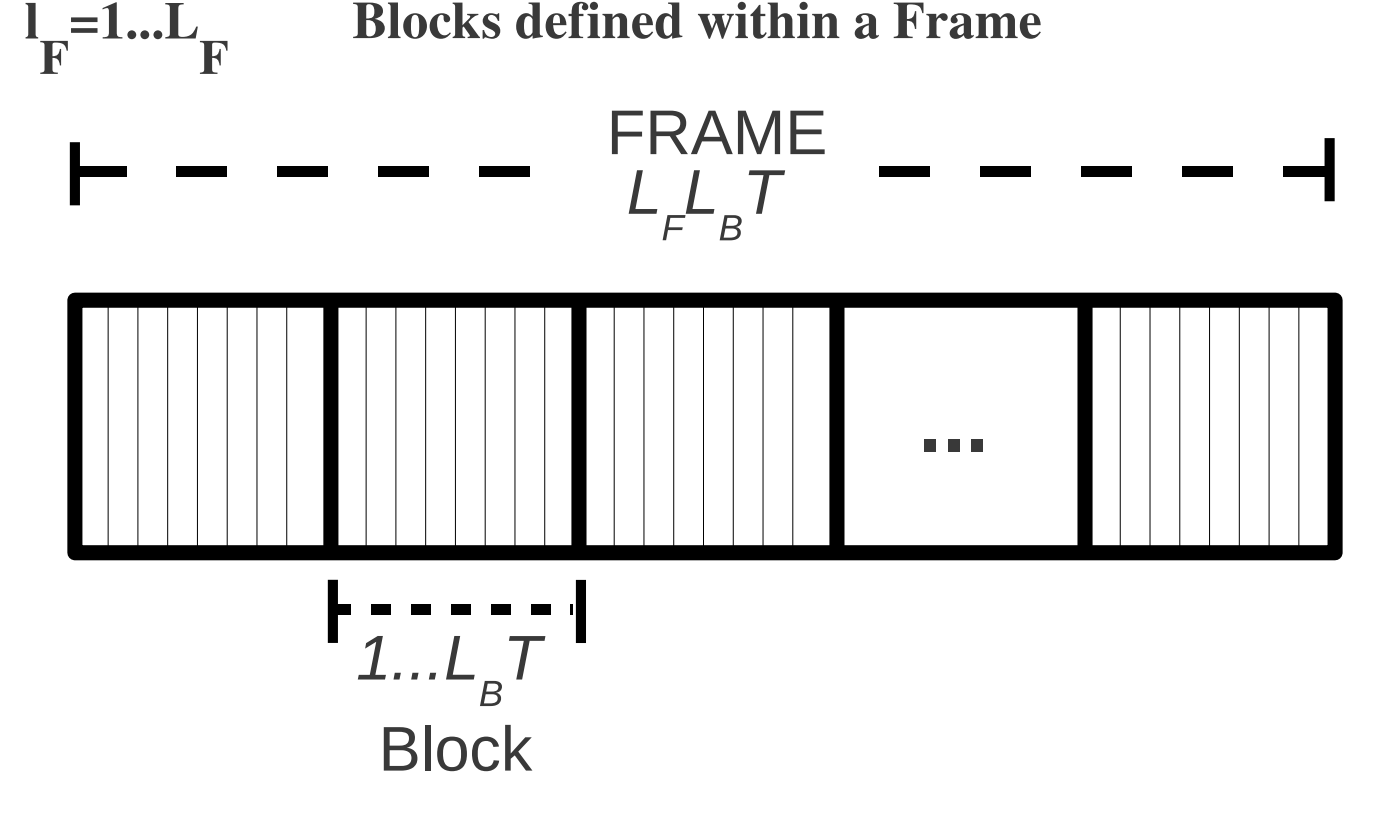

The phase continuity is ensured by an antenna dependent phase memory

$$
\theta_{m, k}=\theta_{m, k-1}+\frac{h_{[k-\gamma]}}{2} d_{m, k-\gamma}+c_{m, k}(T)-c_{m, k}(0) .
$$

Auto-correlation coefficients cancel and cross-correlation coefficients between antennas put to 0

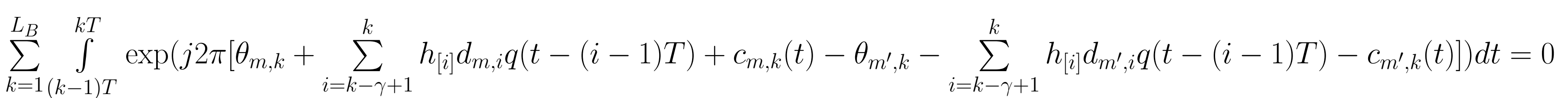

To ease the design, two assumptions are introduced

$$
\begin{aligned}
& \text { 1. } c_{m, k}(t)=c_{m, k^{\prime}}(t) \\
& \text { 2. } d_{m, k}=d_{m^{\prime}, k}
\end{aligned}
$$

For any arbitrary number of transmit antennas, we introduce correction functions $c_{m k}$ as

$$
c_{m}^{l i n}(t)=\frac{m-1}{L_{B} T} t \quad \text { for }(k-1) T<t<k T
$$

For $m=1, \ldots, L_{t}$ and the transited signt takes the form of

$$
s_{m}(t, \mathbf{d})=s(t, \mathbf{d}) \exp \left(j 2 c_{m}^{l i n}(t)\right)
$$

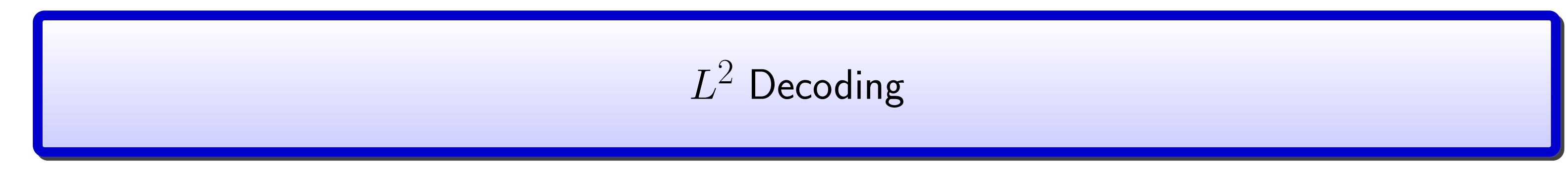

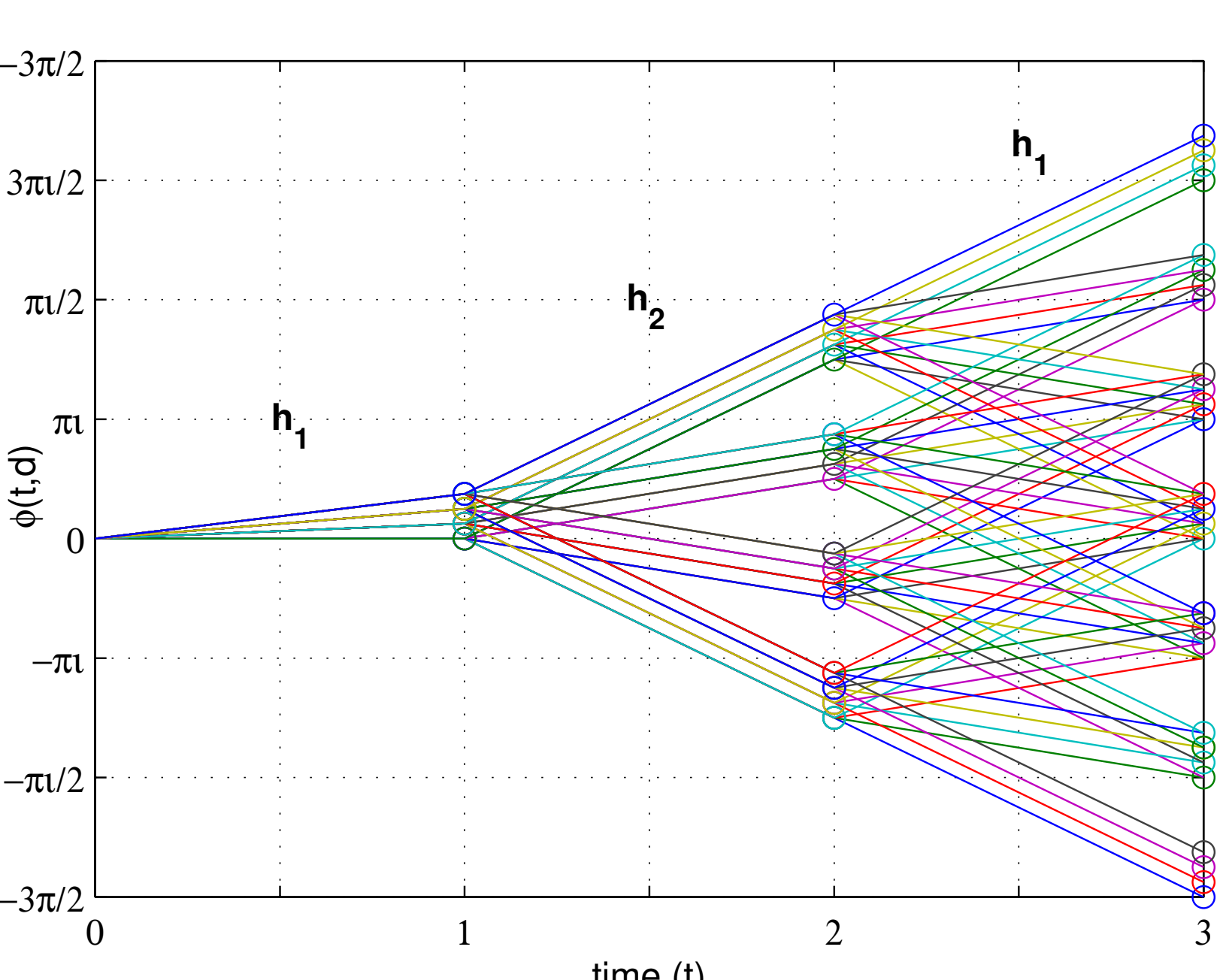

time (t)

FIG. 1: Inner-block phase transition for $h_{1}=\frac{1}{4}$ and $h_{2}=\frac{3}{4}$

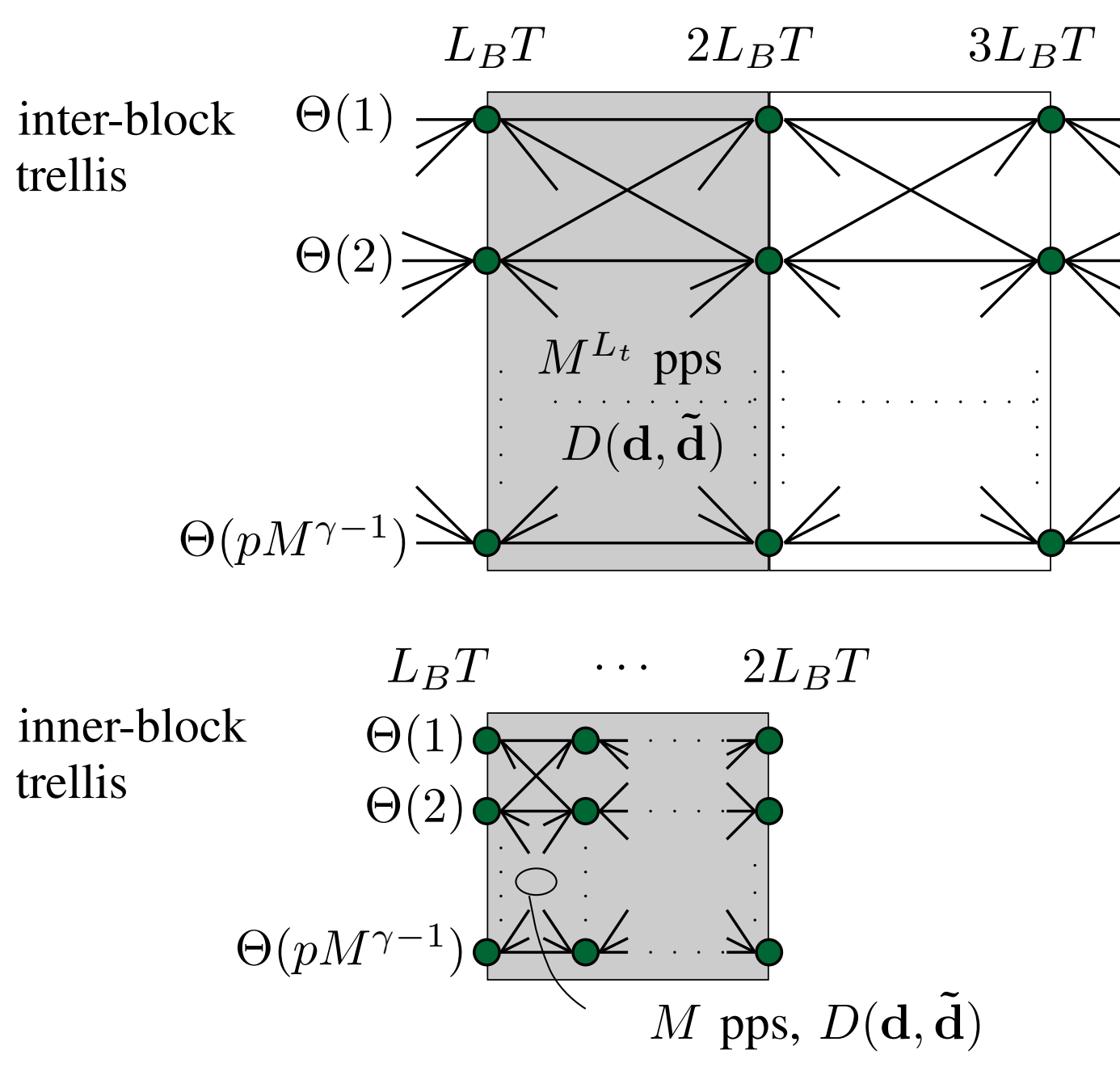

FIG. 2: Simplified detection with $k=1$ ( pps

Classical correlation based multi- $h$ detector expressed blockwise:

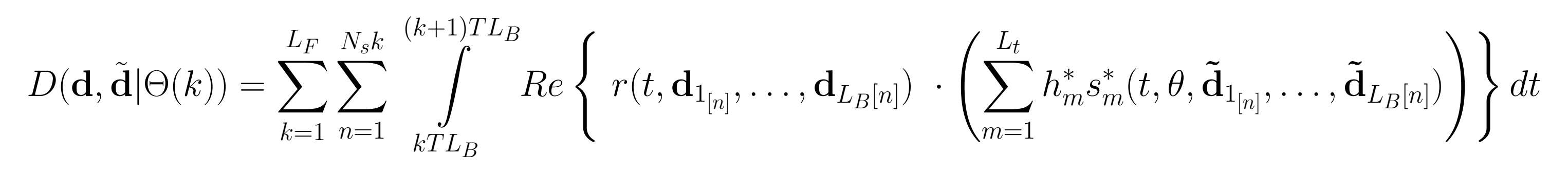

\section{$\ominus$ Impractical:}

$p M^{\left(L_{L} L_{B} N_{s}+\gamma-1\right)}$ matched filters of length $N_{s} L_{B} T$ employed $p M^{\gamma-1}$ times.

$p M^{L_{B}-1}$ states and $M^{L_{B} L_{T}}$ symbols to decode with $N_{s}$ samples each.

$\oplus$ Orthogonality: the cross correlation terms are canceled out with blockwise decoding.

$$
D_{B}(\mathbf{d}, \tilde{\mathbf{d}} \mid \Theta(k))=\sum_{m=1}^{L_{T}} \int_{(l-1) T}^{I T} R e\left\{r(t, \mathbf{d}) h_{m}^{*} c_{m}^{*}(t) s^{*}(t, \tilde{\mathbf{d}})\right\} d t .
$$

To get decoding with complexity growing linearly w.r.t number of transmit antennas, we introduce

$$
x(t, \mathbf{d})=r(t, \mathbf{d}) \sum_{m=1}^{h_{T}} h_{m}^{*} c_{m}^{*}(t)
$$

A simplified expression for a classical multi- $h$ decoder [4] then is given by

$$
D(\mathbf{d}, \tilde{\mathbf{d}} \mid \Theta(k))=\int_{(l-1) T}^{l T} R e\left\{x(t, \mathbf{d}) \cdot s(t, \tilde{\mathbf{d}}) \dot{\phi}_{l}\right\} d t
$$

Hence our detector based on the correlations gives us an expression which maximizes the

$$
D_{r}(\mathbf{d}, \tilde{\mathbf{d}} \mid \Theta(k))=\underset{\Theta(1) \rightarrow \theta\left(p h \eta^{\prime-1}\right)}{\arg \max }\left\{\int_{(l-1) T}^{l T} R e\{x(t, \mathbf{d}) s(t, \tilde{\mathbf{d}})\} d t\right\} .
$$

The simplified detector can now be represented in a similar form as in [5]

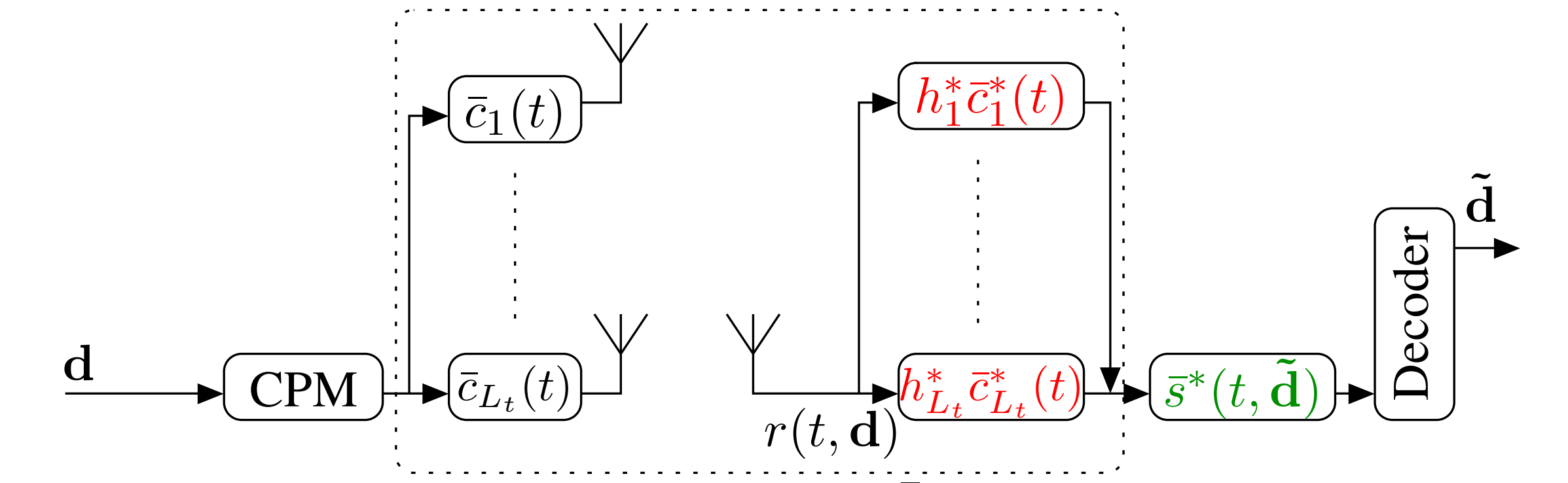

$$
\text { pseudo channel } \overleftrightarrow{H}(t)
$$

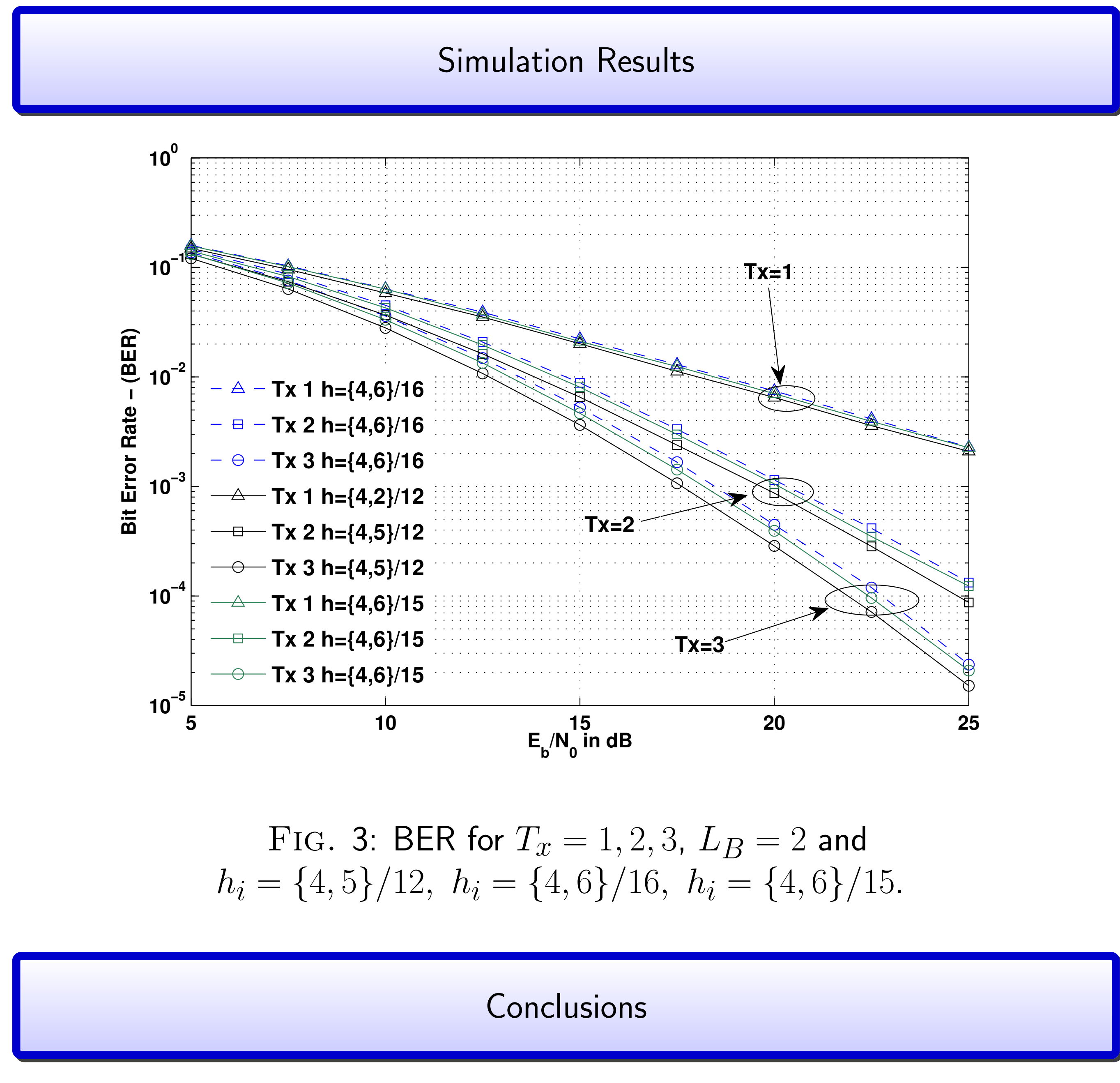

$\checkmark L^{2}$-orthogonal STBC provide full diversity by the construction of orthogonal waveforms. $\checkmark$ We have shown that the inner trellis is equivalent to the inter-trellis for multi-h CPM By choosing $H \leq L_{B}$ we get the largest minimum distance in a block. $\sqrt{ } L^{2}$-orthogonal STBC satisfies the needs for energy and spectral efficiency. $\checkmark \sqrt{ }$ Decoding complexity increases as $P M$ instead of $P M M^{L_{T}}$

\section{References}

[1] M. Hisojo, J. Lebrun, and L. Deneire. Wireless robotics: Generalization of an efficient approach with multi-h CPM signaling and L2-Orthogonal space-time coding. Wireless

[2] M. Hisojo, J. Lebrun, and L. Deneire. L2-Orthogonal ST-Code design for multi-h CPM

Digital Phase Modulation. 1986 [4] J. B. Anderson and D. P. Taylor. A bandwidth-efficient class of signal-space codes. IEEE.

[5] M. Hesse, J. Lebrun, and L. Deneire. L2-Orthogonal ST-Code design for CPM. IEEE Trans. Commun., 2011. 